\title{
Transformative power of mundane technologies in institutional change
}

\author{
Lauri Paavola \\ School of Business, Aalto University \\ lauri.paavola@aalto.fi
}

\author{
Richard Cuthbertson \\ Saïd Business School, University of Oxford
}

\begin{abstract}
To examine the role of mundane technologies in institutional change, we conduct an inductive longitudinal study of a translation in the field of $U K$ grocery retailing and elucidate a process of bottom-up transformation, where customer data replaced product data as a key determinant in decision-making. Our analysis uncovers that such change develops over time through three phases: (1) triggering change through the costs of the technology, (2) capturing value through the benefits of the technology, and (3) retaining transformative momentum through the ability of the technology to develop. While illustrating the process, we show how mundane technologies do not take on new meaning as a result of their innate features but through their relationality in mutual constitution with the field. Hence our study illustrates the fact that each technology holds the potential for generativity.
\end{abstract}

\section{Introduction}

During the past decade, the microfoundations of institutional change have been subject to active research [1] [2] [3]. This has been mainly due to the realization that the role of practices in the creation or change in fields is neither an exclusively top-down or bottom-up process, thus opening up new avenues to understand institutionalization [1] [3] [4] [5]. However, while the current micro-level approaches envisage certain individuals as having the ability to bring about institutional change, technologies, which are often the 'tools' for conducting the action, have mostly been viewed as non-transformational or even inert entities [2] [6]. Studies focusing on technologydriven institutionalization have typically attributed change with the technological innovations [7] [8] and the introduction of new disruptive technologies [9] [10] [11], changing the way work is done. Locking-in to a certain pre-existent technology, on the other hand, has mainly been seen as a reason for organizational stagnation [6].

In the recent literature, there can be found indications that even mundane technologies may hold potential for bottom-up emergence [2] [12]. Especially practice scholars have been active in seeking to capture the interaction between human and nonhuman actants in change [4]. Adopting a practice perspective has enabled institutional research to go beyond the deterministic approach to collective action, in which practices and technologies are seen as diffusing inert objects, being responsible for fulfilling an organization's tasks, without having any transformative role [4] [12]. However, as the focus of this research has predominantly been on understanding the interaction of individual practices and technologies, there is a need to understand how these micro-level developments connect to field transformation.

We attempt to shed light into this gap by studying the unfolding of a specific mundane technology driven transformation from a translational instead of a diffusion logic [15]. In our paper, we follow [16] and define a mundane technology as embedded within its environment, "being intertwined with the reproduction of the normal and the routinized", embodying for example remote controls, automatic door closers, and calculators. In practical terms, we show how a data analytics feature of a loyalty program, built on a relatively simple algorithm, the Rolling Ball, started through cost-cuts in its operating environment to slowly create new insights into customer behavior for the grocery retailer Tesco, the currently largest grocery retailer in the UK. This action conducted by the algorithm hence illuminated the value of customer data to several decision-makers within the organization, leading to its more systematic collection and use. Very quickly, the use of customer data spread to a variety of functions within Tesco, and this data was eventually also shared with suppliers. Through various mechanisms, Tesco's competitors began to implement similar processes, with the result that customer data became the primary determinant in decision-making for the entire industry. As a result, this customer-centric view can now be considered a new norm that is followed not only by most retailers but also by suppliers, whose operations are heavily 
informed and determined by the customer data collected by retailers.

In our findings, we uncover that a change created and sustained by mundane technologies is a process that develops over time through three phases: (1) triggering change through the costs of the technology, (2) capturing value through the benefits of the technology and (3) retaining transformative momentum through the ability of the technology to develop.

\section{Theoretical background}

Several recent studies have focused on linking practice-based research with institutional theory to advance our understanding of individuals and their actions on institutional change [3] [17]. For example, Gawer and Phillips [17] identified different forms of institutional work at Intel, while it moved from a traditional supply chain logic dominated by computer assemblers to a new platform logic following very different organizing principles. The study uncovers the connection between various forms of institutional work and the subsequent shifts in field-level institutional logics. Similarly, Smets et al. [3], by means of their case study of a law firm, have shown that change may come about via reflexive attempts by individuals to solve problems in their mundane day-today activities. Their study illustrates three different mechanisms through which mundane work became justified and diffused among lawyers in the field of law and legal services. These mechanisms are variously termed situated improvising, reorienting the normative network, and unobtrusive embedding, the latter referring to a change "radiating" beyond an organization in an effective or "unobtrusive" way to cause change at the field-level. More recently, e.g., Cardinale [18] and Haack et al. [1] have seen everyday mundane and routinized practices as drivers of institutional change; when practices evolve, institutions are seen to change.

Another stream of literature has focused on understanding the link between technologies and practices. In this stream, for example Schneiberg and Lounsbury [19] have shown how practices can be considered as non-deterministic drivers of technological diffusion within fields. Subsequently, the paper suggests a shift in institutional theory from the "isomorphic world of diffusion" to viewing fields as sites of contestation. On the other hand, Labatut et al. [4] have seen the influence of technologies on practices as a combination of three dimensions (technical substrate, managerial philosophy and organizational model), hence furthering our understanding of change to the other direction - the role of technologies in the (re-)creation of practices. Overall, practice-based studies connecting human and non-human actants have emphasized the relative importance of materialism and agency in the process of change. The impact of technologies as non-human actants are seen to arise from their entanglement with actors through different socio-technical relations [12]. Although technologies are most commonly evaluated through their outputs and performances [13] [14], for example, Labatut et al. [4], see also references therein, have discussed that the nexus between the human and non-human is also created through various assumptions, rational myths, belief systems, and different institutional forces acting as vehicles for change. Moreover, payoffs and uncertainties related to the use of technologies are often seen as the most important dimension in their renewal decisions [9].

While the above links imply co-constitution among non-deterministic technologies and institutional fields, various adjacent literatures point to the same direction too. For example Foucault's notion of governmentality in political research has been considered to be reflected on institutionalization processes [22]. He has argued that technologies are not mere artefacts disconnected from broader intentions, knowledge systems or rationalities - they are proposed to have roles in bottom-up emergence through the constitution of power and knowledge. We attempt to contribute to this gap in institutional theory by illustrating and analyzing a process of technologydriven institutionalization.

Following the practice path, which has proved insightful for the purpose as discussed above, we study the unfolding of the transformation from a translational instead of a diffusion logic focusing on micro-level developments that led to changes [15]. In the translation literature, practices and technologies are seen to be transformed as they become embedded in new organizational environments, being then further transferred to entirely new fields where given a different meaning [23] [24]. While a diffusion logic considers transformation processes as relatively linear and often sees technologies as deterministic, a translation approach assumes that novelty and the power of technologies arises through a complex network of relations between actors and their outputs and, hence, in-the-making [23]. For example Pallas et al. [24] in their study focusing on a translation process, highlight the importance of understanding the translated entities as loosely coupled systems, with the distinct elements producing very context specific outcomes. The same phenomenon can be seen in the afore described connections between human and nonhuman actants [4] [9]. Overall, a translational 
perspective assumes that changes cannot be explained by macro-level approaches only as they predominantly focus on organizations and their relationship [25]. All of this indicates that even the most mundane technologies may possess transformative capacities when taken to different organizational environments. Hence we ask the research question, how does a mundane technology-driven institutional change unfold in practice?

\section{Methods and data}

We adopt an inductive theory-building approach in our study on the role of mundane technologies in an institutional transformation process [26] [27]. As we are interested in understanding the relationship between micro- and macro-level dynamics, we take a practice perspective focusing on everyday activities and their consequences across different levels. Accordingly, our study requires close-up engagement with practitioners as well as knowledge of the broader context and network of the focal organization throughout the time under investigation [28].

\subsection{Research setting}

The case of UK food retailing provides a particularly interesting empirical setting, as it can be considered the frontrunner in a global transformation, where customer data increasingly replaced point-ofsales (POS) data in most retail functions. The UK retailers were the first to embrace the change in operational principles and can today be considered as a space where the decision-making processes of most companies have, to a certain extent, become embedded in customer data analyses. As a result, the focus of grocery retailers and suppliers has seen a field-level shift from products to customers, with different loyalty programs operating as vehicles for change.

The transformation was initiated years after Tesco launched its Clubcard in 1995 [29] [30] [31]. The introduction of the program, which by no means was intended to be transformative, arguably later provided Tesco with a valuable edge that was instrumental in steering the company into profitable new business areas, forcing the other retailers to follow suit. After an exploratory phase, during which the mundane algorithm under study was routinely applied for calculating discounts and customizing vouchers, the focus slowly shifted to its exploitation, not only by the retailer but throughout the supply chain [30] [31]. Finally, many of the data analyses became automated and were thus embedded as drivers of change within the organizations. Currently, customer behavior is seen as the key driver of development, with data being automatically collected and analyzed at every touch point (store, app, website, contact center, email, and social media) in ever increasing volumes.

\subsection{Data and analysis}

Due to the longitudinal nature of the research study, it relies on a large amount of data derived documented in the archives of our case companies, which are combined with data collected from a variety of public sources. Archival data is particularly suitable for longitudinal process studies where the past development of an entity is being observed over a long period of time [28]. After analyzing voluminous written documents, chronologies have been constructed of the past developments. The archive material was complemented by a number of meetings and informal discussions, during which the collected and documented data were repeatedly consulted.

In addition to the meetings and documents that provided us with evidence on what was happening in the field at that time, we conducted interviews for evidence of the sensemaking in retrospect. In choosing the interviewees, we particularly focused on informants who have been closely involved in the introduction of the use of customer data and its impact on the customer offer. We have striven for maximum accuracy and legitimacy [26] by comparing the individual interviews. In cases of contradiction, respondents have been contacted for further clarification.

Meetings. We attended a total of 108 management meetings between years 1993 and 2016. During and in preparation of those meetings, we were often asked for our own observations and insights on the process. Multiple times, we followed up on particular details with people who participated in the meetings. These debriefings provided very valuable insights into to how people felt about the content of the meeting and the decisions made. Further, being on site also allowed us the opportunity to observe employees carrying out their daily tasks. A particular focus of these interactions was in our encouragement of employees to enlighten us on the activities involved in carrying out their role, and asking them to explain how they had adapted their practices in the light of the customer data that had become available. This produced many confidential (and often commercially sensitive) notes, as well as some publicly available case studies that turned into documents for our study.

Documents. We had access to various internal company documentations regarding the use of customer data. Other publicly available documents included annual reports, news articles, magazine 
interviews, and books, including Scoring Points by Clive Humby, Terry Hunt and Tim Phillips (2008). Documentation from a variety of sources was analyzed throughout the whole time period from 1990 to 2018, which started before the industry had made any attempts to collect and use customer data.

Interviews. Between 2014-2019, we conducted 19 interviews that focused on the role of data analytics technologies and its role in creating customer data. Focusing our research on specific practices, we designed a list of semi-structured interview questions that were used throughout the interviews. We prompted interviewees to reflect on the changing role of customer data in everyday operations, how its use had changed the daily practices, how the data challenged the established ways of working, and how all of this affected other organizations and customers. The interviewees were asked to provide their views on the phases of change through which the field and individual organizations passed, and to explain causeand-effect relationships related to these changes. We compared the interviews with secondary data, such as archival documents, and in cases of contradiction or vagueness we asked the interviewees for further clarification. As a result, a consistent picture emerged and eventually there were no major contradictions. We ended the process when new insights no longer emerged, and the saturation of our particular focus could be considered as having been achieved.

The interviews lasted between 30 minutes and 2 hours and resulted in approximately 17 hours of interview material. All interviews were transcribed verbatim. The interviews provided a consistent picture and no major contradictions arose. We stopped the process after 19 interviews when no new insights emerged and we considered saturation of our particular focus to be achieved. In an iterative process during which both authors were involved, we analyzed and coded the interviews individually and crosschecked our readings, going back and forth between theoretical concepts and empirical data. Based on our analysis, we were able to divide the past development into three phases that resulted to translation. Our data does not represent a realist account but rather an inductive narrative based on how managers and senior executives have interpreted the change and envision the future.

\section{Findings}

We will next present how the retailing industry has gone through a transformation over the last 25 years and since the introduction of a systematic collection of customer data. Along the lines of the different phases of this transformation process, we focus on how people narrate and interpret the impact of algorithmic technologies and its journey in transforming the organizing of retailing. While doing this, we uncover that a change created by mundane technologies is a process that evolves over time through a sequence of three phases: (1) triggering change through the costs of the technology, (2) capturing value through the benefits of the technology and (3) retaining its transformative momentum through the ability of the technology to develop. All of this can, finally, results to a field-level change, where the entire operating logic in grocery retailing has been transformed.

\subsection{Phase 1 - Introducing customer data}

"Typically, a branch manager would sit down and have a monthly meeting or whatever with their boss, the Regional Head of Operations. They would look at the P\&L, they'd talk about sales, they'd talk about wastage, they'd talk about pay, which are the kind of elements on the profit and loss account [...] but never about customers, unless you count sales as a customer measure." (L)

Until the early 1990s, Tesco, like the other grocery retailers in the UK, collected and relied on point-of-sales (POS-) data but in 1994 Tesco began a collaboration with a small data analysis company called Dunnhumby to launch a loyalty program known as the Clubcard. The plan was to enhance customer loyalty in the increasingly competitive grocery retailing market. Based on their experience from an American software business (software engineering), the founders of Dunnhumby were able to "show the Tesco board that their tiny business had the software and skills to do something the supermarket group hadn't been able to do for itself - work out almost exactly what Tesco's customers were buying." This allowed a feature for the program for the collection and analysis of customer data, which enabled Tesco to provide customized offers upon that was vastly more detailed than that offered by POS-data.

When the loyalty program was first launched, customers could sign up for their Clubcard at one of Tesco's stores. They were required to provide their names and addresses, as well as information on their age, the size of their families, etc. Such information would allow Tesco to identify which customer had made each transaction performed at one of its stores. "If you go into a store and you buy an average number of items, say 20 items, from the Tesco's on Cowley Road and if you bought 20 items with your Clubcard or even without your Clubcard, you would generate 21 lines of data. There's one line of data that says [John] 
went in at 12:30 on a Wednesday and he paid cash. Then there's one line of data for each of the 20 items I bought that says it's Cheerios, 300 grams, and I paid £1.99." (F)

By making purchases at Tesco, customers would accumulate points that were converted into targeted discount vouchers that Tesco would mail to the customers several times each year. When paying at the till, not only would the products purchased by a customer be swiped, the customer's Clubcard and any of the discount coupons they were using would also be registered. To operate the analytics feature of the process, Dunnhumby introduced an algorithm called the Rolling Ball for customizing the offer.

"We use an algorithm, called the Rolling Ball, which draws links and common patterns between different products. For example Alphabetti Spaghetti would class as a 'family' product. By knowing that it often appears in a basket alongside a breakfast cereal like Coco Pops, Dunnhumby would assign a stronger 'family rating' to Coco Pops." [29]

The customer data processing initially amounted to a rather simple algorithmic process designed to increase loyalty. The automated process of Tesco applied the gathered information to provide more customized discount coupons and hence to serve customers better. As explained by Hayward [29], "Thanks to the Rolling Ball algorithm, a unique DNA profile for each Tesco shopper was created". The process was operated alongside but separate from Tesco's other processes such new product development, pricing and design of promotions.

For the first years, the algorithm was nothing more than an automated process recording customer transactions, calculating individual purchases and assigning customized vouchers accordingly [30]. Due to the high maintenance expenses of running the analyses and the simultaneous need to cut costs in Tesco, there was an internal pressure to terminate the program or alternatively find more ways to utilize the accessible data. According to one interviewee, the investment became heavy "when falling grocery prices have squeezed margins on [Tesco's] core business."

"The cost of rebate is only one overhead of a loyalty programme...there are the costs of managing a programme - investment in systems, fulfilment support, and so forth...many retailers seriously underestimate the full costs of setting up and sustaining loyalty programmes (which were at the time $£ 300$ million/year)." [30] The ability to send slightly more customized coupons (to initially 4 different customer segments) instead of sending alternating vouchers (to provide occasional offers for every customer), did not seem worth continuing the investment from the shareholders perspective. At the time it seemed likely that the Clubcard program would need to have continued forward with lowered dividends and without the data-analytics feature, with coupons being sent but not customized [30]. The increased internal pressure on Tesco's senior management sparked research to look for other potential uses of customer data.

As a result, "we [Dunnhumby] started working with the commercial teams in Tesco to think about where customer data could speed up or improve things." (C) The ultimate goal was to figure out whether there were potential uses for customer data in the commercial teams. "We had an R\&D sort of team that were looking at the things that were interesting...We basically had a monthly presentation to Richard, Tim and Terry [Tesco's senior management]...these are the things we are finding... and we think you should put more effort behind this one and this on. And then, they normally form a project team to support that." (C) With new research, the use of customer data slowly advanced. First it proved useful in informing new product development since it provided the first opportunity to observe whether the same customers would buy a new product for a second time, thereby more accurately indicating whether a new product was going to be a success. "This was obviously something that traditional product sales data was unable to do" (F). Customer data was later also relevant to the area of pricing. Through this data, Tesco realized its customer-base consisted of several distinct groups, some of which were highly price sensitive while others were not. Thus, Tesco could start to adjust the pricing of its products in a more flexible and efficient way. "For example, contrary to the traditional pricing method of lowering prices on some of the biggest-selling items in order to attract more customers, Tesco could now focus on the products that were popular among priceconscious shoppers." (C) A similar development took place in promotions, which could likewise be efficiently targeted at specific customer groups.

"Retailers at the time obviously knew how much they were selling of a particular product, but the key point is that they did not know what combination of items consumers were typically buying. Dunnhumby was able to provide this information."

The new advances in the use of data enabled Tesco to "double its market share in little more than a year, to overtake Sainsbury's and become the UK's largest retailer, and transform the way many of us shop." As a result, competing companies followed Tesco in their initiative, with different programs being launched in the UK as well as globally. Due to rapidly developing computing power, retailers gained access 
to larger amounts of data and a pool of customer information that was unavailable until quite recently. One of our interviewees who worked at Tesco back in the 1990s explained that "computers back then could only process $0.5 \%$ of the barcode level data." (F)

In our analysis we concluded that the transformation of the field of UK grocery retailing was not primarily initiated by any external factor, even though technological development had a part to play. Instead, the decisions to implement customer data analytics and to later utilize the results were taken by Tesco's management. The studied technology was an algorithm that initially provided a mundane and mechanical process for the customizations of offers to Tesco's 4 customer segments based on past shopping transactions. However, the running costs of the algorithm became too significant during Tesco's price cuts, and this sparked the drive to gain more strategic and operational benefits for the resulting customer data by using it to inform the design and offer in Tesco's stores. Before the cost cuts at Tesco, the rolling ball algorithms was highly institutionalized and incapable of producing an output beyond "normal or routinized", making it seem evident that its transformative impact was triggered by the way it relates to relevant actants. Without the high running costs, its operation would have remained unnoticed by the senior management in the large organization of Tesco.

Hence we argue that the cost of running a mundane technology is often the first trigger in its transformative impact.

\subsection{Phase 2 - Working with customer data}

The increasing computational power gave retailers further abilities to better understand detailed customer data and make connections between events and activities that were not noticeable before. Thanks to the ability to collect a larger amount of more specific data, "retailers began to develop customer segmentation models", that is, categories of customers based on geographic and demographic data. I

As the field of data analysis further evolved, they added behavior variables to this categorization and enabled the move from 4 to 27 different customer segments, providing an even deeper understanding of customer needs. Overall, customer segmentation models slowly developed to help retailers divide customers more accurately based on their needs and preferences. This was no more only for the purposes of providing customizing, but now most importantly for developing the in-store offering. As explained by one of our interviewees, "we have found through our work with our retailer partners that the impact of retail decision support is 5-10 times more significant to the business than 1-1 communication." (A)

Today's technologies allow for even more detailed understanding of customers' needs and behaviors, which allows retailers to provide even more customized services. As one interviewee said: "The biggest change that came about with the growth of data [...], is that you're now able to much more effectively connect their behaviors and attitudes." (D)

Hence, over time, the use of customer data had a more and more profound influence on most of Tesco's processes and operations, and this eventually amounted to organizational transformation, where the focus of analyses slowly shifted from products to customers.

In the next phase of the development, the transformation spread to the suppliers. As emphasized by one of our interviewees, "while the available information on customers is definitely useful for the retailers as such, it becomes even more powerful when used by the various actors throughout the supply chain." (G)

The sharing of customer data and analyses with supply chain partners was pioneered in the UK, indeed perhaps globally, by Tesco. As time went on, Tesco's suppliers became interested in the data Tesco had collected about their customers. The moment when retailers started sharing the data with their supply chain marked a real turning point. This changed the entire relationship between retailers and suppliers which, through history, was based on the same question - how cheaply can a supplier provide a product to the retailer.

As one interview put it: "I think what some of the pioneers in this area realized was that, despite the fact that they're always going to negotiate on price, there was actually benefit in working together because at the end of the day, it was a combination of the efforts that delivered the customer experience." (M)

It was in 2002 when Tesco allowed their data analytics company Dunnhumby to provide anonymous access to their data to FMCG (FastMoving-Consumer-Good) companies. "This brought Tesco much closer to suppliers such as Mars, Heinz, Unilever, Protect \& Gamble, and others." (F) Moreover, this move helped Tesco better understand their data insights and how they relate to their relationship with the suppliers. Suppliers were willing to pay Tesco for the customer data, which proved to be far superior to the data and analyses that suppliers had formerly used when developing new products or creating promotional campaigns. Moreover, a significant benefit came from the fact that "the retailer and supplier could now speak the same language when 
discussing customer segments, sales performance metrics, etc. (M)

It was apparent that sharing data and insights had a great impact on how retailers and suppliers worked together on new product development and assortment. For instance, each time a customer purchased an item, a data stream was created to inform the suppliers of the change in the system. With that level of data sharing set in place, the suppliers were able to organize the production more precisely and thus enhance the entire supply chain while allowing retailers to make continuous sales.

After asking some of our interviewees to describe the use of these data streams and how the whole system worked in practice, we learned that also Sainsbury's had adopted the Tesco model, and now all their suppliers have access to customer behavioral data. "So we said to Sainsbury's, listen, you are not, well you are not maximizing the use of the data. Why not we set up for you a company that can do for Sainsbury's what Dunnhumby does for Tesco." (K) The suppliers do, however, have to pay to get access to data although the benefits of the shared analysis are mutual. The joint interpretation of the same metrics allows retailers and suppliers to discuss their objectives more accurately. The result of such shared efforts are mutual and they include the increase of sales and better customer satisfaction.

As an example, one interviewee mentioned the retailers' focus on promotions that led to substitution behavior among the customers. For example, if the retailer creates a special offer for Coke, they will sell more Coke but less Pepsi. "The customers might purchase more Coke under the influence of the deal but, in reality, the retailer will still be selling the same amount of stuff because their Pepsi sales would drop." (B) In regards to this, the retailers are encouraging their suppliers to fund and design promotions in a way that will increase the sales of an entire category of products, not only specific products.

Overall, we concluded that even as the change brought about by the Rolling Ball algorithm evolved into an industry-level change, this occurred incrementally rather than at a specific moment. As a result of internal pressure, Tesco and Dunnhumby gradually learned more about the analysis of customer data and developed its use, which first impacted on Tesco's processes and this led to change at organization-level. We see here how the role and relations of a technology can lead the processes participants to ask new questions and update the intentions that are related not only to that particular process (such as the analytics feature of the loyalty program) but also to other processes (such as e.g. NPD and pricing).

Later these changes also impacted the competitors and suppliers. Indeed, our findings suggest that the ability of a mundane technology to take higher-level transformation further depends on its ability to impact other processes. The other processes may be closelyrelated within an organization; thus, within Tesco, the customer data largely replaced the point-of-sales data that had previously been used to inform pricing, promotions, etc. On a theoretical level, it is interesting to note that these latter processes were not exogenously recreated but simply became more effective when they were running based on customer data instead of point-of-sales data. They therefore carried the impact to the extent that change also occurred across organizational boundaries. For example, competing companies (e.g. Sainsbury's) observed the advantages of using customer data and introduced analogous programs of their own. If other uses for the data would not have been found, the analytics feature of the program would have been terminated.

Hence we argue that after gaining new momentum and increased scale, the benefits of a mundane technology is the catalyst for its further transformative impact.

\subsection{Phase 3 - Customer data-driven decision- making}

Our discussions with the interviewees revealed the most recent advance in the use of data - the automation of data collection and analysis. It was determined that the longer a retailer worked with customer data, the more automated the entire process became. We also looked into the potential future of data usage in this sense and one of our interviewees mentioned that data-related services will be mainly embedded in algorithms.

For the 90's, it was the computing power that limited the advances of the customer data use. "Then it was not until about 2003 that we were able to look at $100 \%$ of the data." (C) From that day until today, the computing power enabled the Rolling Ball algorithm to look into all shopping transactions. "That obviously had an impact. Then for several years we were on top of things because our computer could handle all the data." (F) As no transactions were missed, it was for the first time possible to for example assess the impact of a specific advert on an individual customer in a reliable way. Through these advances, it was possible to take the tailoring and customization of offers to an entirely new level. Obviously, such tailoring of offers in real time requires a huge amount 
of continuous decisions and hence automated decision-making. "So we need to set up to be able to get the data to do that but then also have the data science, the machine learning algorithms and the whole setup to be able to deliver on that in the blink of an eye." (F)

Our interviewees addressed that customer-centric algorithms are in fact the most reliable source when it comes to making customer-based decisions. In essence, a data algorithm is a much better foundation for future decisions than a random store manager's "creative idea or gut feeling." (L) Furthermore, real time data plays an enormous role in the whole process because it keeps the methods and decisions efficient within current situations. Human agency is no longer the best way to provide real time data. The reason behind this is that "businesses need to have full oversight over materials at every step of the supply chain in order for it to function effectively." (M) This can only be achieved with automated data collection algorithms that allow businesses to quickly and precisely determine product locations in real time.

Online shopping can serve as a great example here. Statistics show that people are likely to add additional items to their shopping list until the actual day of delivery. In a traditional setting, a customer who brings a list to a physical store is more likely to make additional off-list purchases than someone who is shopping online.

Obviously, retailers are looking for ways to encourage their online shoppers to make additional purchases as well. This can be done with the help of algorithms that push notifications to remind online shoppers not to forget items on their list or to provide them with examples of similar products they might be interested in.

As one interviewee explained it: "What we did was we analyzed people who would made a big purchase online, and then within the next couple of days had been into a store to buy just one or two items with the idea that this would be an indication of the types of products that people might have forgotten." (F)

The overall goal is to create a unique and convenient shopping experience for the customer, which includes benefits of both physical and online shopping. Tesco has already set up their own service to push this goal and, even though the realization of this idea is still in its early stages, the service is creating revenues although it is completely based on algorithms. Another example of using analytic models in retail stores is the fact that many retailers use weather data to stock their shelves. With insight to data such as the history of customer behavior and expected temperatures, businesses can predict what people in certain regions or areas would like to purchase.

Whereas the analyzed Rolling Ball algorithm initially provided insights by looking at $0.5 \%$ of the barcode level data, the computing power now allows all transactional data to be analyzed, enabling further competitive advantage through wider and more accurate real time applications. This has amounted to a fundamental shift in the overall logic of decisionmaking in the field of retailing; a shift that is now followed by most retailers and suppliers. Hence our findings illustrate, not only can customers' actions be considered a central factor in what becomes offered in stores, but customer behavior and the retailers' reactions to it have become so embedded in the advanced data analysis process that these may no longer be visible to managers. The technological developments have thus facilitated the functioning of the Rolling Ball algorithm, shifting power and agency to customers, who are effectively no longer mere customers but also co-producers and co-suppliers now participating and sharing responsibility for production and supply decisions.

Finally, to sustain its momentum, we argue that the technology needs to be able to develop, in order to continue providing value in the evolving environment.

\section{Discussion and conclusions}

Our findings suggest that whether a mundane technology becomes a trigger depends on its role and relations with the surrounding environment. In reality, when Tesco first launched the Clubcard and the Rolling Ball algorithm was introduced, there were a lot of unknown aspects surrounding it and its operations produced significant costs for years. Further, its transformational power was not known a priori. The overall process was originally intended to reward Tesco's customers based on what they bought and to gather information on their shopping behavior to offer targeted discounts and to hence increase loyalty. However, as the use of customer data intensified, it started to provide Tesco with insights that no-one else had at the time. During the time when other UK grocery retailers were not yet actively analyzing customer data, Tesco's view of the world was quite different to that of its competitors. Most importantly, Tesco's ability to not only understand and communicate with individual customer segments but also to influence their shopping habits set it apart from other grocery retailers.

The main contribution arising from our findings is that mundane algorithms can result in a field-level transformation. We discuss this contribution to the 
literature via the following three topics: (1) We discuss how mundane technologies can drive field-level changes, (2) we theorize the studied transformation process as translation, and (3) we discuss future research in the light of our findings.

\subsection{Technologies as drivers of field-level transformation processes}

We contribute to the current understandings of technology-driven transformation processes. As discussed in the background literature, technologydriven field-level change has typically been attributed to the introduction of technological innovations [7] [8] or novel disruptive technologies [9] [10] [11]. On the other hand, "locking-in" to a certain pre-existent technology has been considered to result in organizational stagnation [6]. Our case study complements these understandings by illustrating a transformation process that is driven by a mundane pre-existent technology.

The transformation process was initiated by the costs of the analyzed Rolling Ball algorithm in the changing environment of Tesco. However, the role of costs in not a new aspect to technology initiated transformations. Whereas we have witnessed the costs related to the use of the technology as the driver for change, past research has had an opposite view. For example Christensen [9] has related the tendency of sticking with existing technologies to maximizing profits by keeping the status quo. They have considered that devoting resources to new technologies increases uncertainties and costs. Whereas our study confirms costs as an important socio-technical dimension related to decisions regarding technologies, we contribute to the understanding by showing that technology associated costs can also lead towards transformation while the technology is used. Hence our results imply that management should not only consider costs as a burden in investment decisions, but also as drivers of the technologies further impact.

The costs acted as a trigger for the change process at Tesco. For the transformation to advance, the algorithm had to fulfill its new role in Tesco's marketing processes (e.g. pricing, promotions, NPD), as well as to match with the requirements of the changing technological environment. This is in line with the current understandings technology- and datadriven change. For example Etzion and AragonCorrea [20] show how data analytics reinforce organizational sustainability and how different operational, strategic, and corporate activities are affected in this process. Moreover, and McAfee, and Brynjolfsson [21] discuss how Big Data can directly translate into improved decision making and organizational performance. As the computing power advanced, the Rolling Ball provided more detailed insights and stayed thus in par with the development.

Overall, our study highlights the transformative power of mundane technologies in change processes. We have illustrated how mundane technologies do not only take on meaning as a result of their innate transformative features but through the relationality of mutual constitution over the transformation process [2] [32]. Through changes in the environment, we argue that all the numerous technologies we have embedded in our organizations hold potential for transformation.

\subsection{Interdependence of technologies within and across organizations}

We theorize the studied transformation process as translation. Following the translation logic, the running costs of the algorithm became too substantial while embedded in the operations of Tesco where margins were simultaneously squeezed, hence given a new meaning, and further transferring into a wider field-level transformation [7] [23] [24]. This sheds light on the relatively unexplored question of how mundane technologies can bring about higher-order or institutional change and points to the fact that each technology holds potential for generativity. Unlike previously studied practice-driven processes of institutional work, institutional entrepreneurship [33] or practice theory [3], where action leading to the creation, or alternatively transformation, of institutions is driven by human consideration by either intentionality or reflexivity, the change in our case was not purposeful, but triggered by the existence of a mundane and initially separate algorithm. Furthermore, while technology-driven transformation processes have typically been seen linear and technologies considered as deterministic [7], our translation approach views that the transformative power of mundane technologies arises through a complex network of relations between actors and their outputs, similarly as any other human led transformation [3] [2] [23] [24]. Our study underlines this relational nature of technologies. For example, Tesco's pricing routine affected its sales operations, which then affected Tesco's range routine while also affecting customer routines.

Taking such a relational perspective is useful because it does not focus on the aggregation of technologies in the sense of a mere accumulation of stable entities. Instead, it acknowledges that as technologies are used, they interact with surrounding actants, creating generative forces [32]. Our empirical 
findings support this conceptual shift, which is less concerned with bringing together the "right" technologies to fulfill a task and more to do with how these technologies and their outcomes feed into each other, potentially leading to changes within an organization or, as we have seen in our case, even the transformation of an entire field.

\section{References}

[1] Haack, P., J. Sieweke, L. Wessel. 2019. Microfoundations and Multi-Level Research on Institutions, Emerald Publishing Limited.

[2] Powell, W.W., C. Rerup. 2016. Opening the Black Box: The Microfoundations of Institutions, In Greenwood et al. (Eds), The Sage Handbook of Organizational Institutionalism 2nd Edition. London: Sage.

[3] Smets, M., T. Morris, R. Greenwood. 2012. From Practice to Field: A Multilevel Model of Practice-Driven Institutional Change. Academy of Management Journal, 55: 877-904.

[4] Labatut, J., F. Aggeri., N. Girard. 2012. Discipline and Change: How Technologies and Organizational Routines Interact in New Practice Creation. Organization Studies, 33(1): 39-69.

[5] Scott, R.W. 2008. Institutions and Organizations: Ideas and interests, Thousand Oaks: Sage.

[6] Patala, S., I. Korpivaara, A. Jalkala, A. Kuitunen, B. Soppe. 2019. Legitimacy Under Institutional Change: How incumbents appropriate clean rhetoric for dirty technologies. Organization Studies, 40(3): 395-419.

[7] Garud, R., P.R. Nayyar, Z.B. Shapira. 1997. Technological Innovation: Oversights and Foresights. Cambridge: Cambridge University Press.

[8] Schilling, M.A., R. Shankar. 2019. Strategic management of technological innovation. McGraw-Hill Education, New York.

[9] Christensen, C. 1997. The Innovator's Dilemma: When New Technologies Cause Great Firms to Fail. Cambridge, MA: Harvard Business School Press.

[10] Kostoff, R.N., R. Boylan, G.R. Simons. 2004. Disruptive technology roadmaps. Technological Forecasting and Social Change, 71(1-2): 141-159.

[11] Kumaraswamy, A., R. Garud, S. Ansari. 2018. Perspectives on Disruptive Innovations. Journal of Management Studies, 55(7): 1025-1042.

[12] Glaser, V.L., R. Valadao, T.R. Hannigan. 2021 (forthcoming). Algorithms and routine dynamics. In D'Adderio, L., K. Dittrich, M.S. Feldman, B. Pentland, C. Rerup, D. Seidl. (Eds.) Cambridge Handbook of Routine Dynamics, Cambridge, UK.

[13] Paavola, L., R. Cuthbertson. 2021. Algorithms creating paradoxes of power: Explore, exploit, embed, embalm. Information Systems Management. DOI: 10.1080/10580530.2021.1939200.

[14] Paavola, L., R. Cuthbertson. 2018. Routines as drivers of adaptation, incremental change and transformation. Academy of Management Proceedings, 2018(1), 15686.
[15] Callon, M. 1986. Some elements of sociology of translation: Domestication of the scallops and the fishermen of St. Brieux Bay. In J. Law (Ed.), Power, Action and Belief: A New Sociology of Knowledge?: 196233. London: Routledge \& Kegan Paul.

[16] Michael, M. 2003. Between the Mundane and the Exotic: Time for a different sociotechnical stuff. Time \& Society, 12(1): 127-143.

[17] Gawer, A., N. Phillips. 2013. Institutional Work as Logics Shift: The Case of Intel's Transformation to Platform Leader. Organization Studies, 34(8): 1035-1071.

[18] Cardinale, I. 2018. Beyond Constraining and Enabling: Toward New Microfoundations for Institutional Theory. Academy of Management Review, 43: 132-155.

[19] Schneiberg, M., M. Lounsbury. 2008. Social movements and institutional analysis. In R. Greenwood, C. Oliver, K. Sahlin and R. Suddaby. The Sage Handbook of Organizational Institutionalism, Sage Publications Ltd, 650-672.

[20] Etzion, D., J.A. Aragon-Correa. 2016. Big Data, management, and sustainability: Strategic opportunities ahead. Organization \& Environment, 29(2), 147-155.

[21] McAfee, A., E. Brynjolfsson. 2012. Big data: The management revolution. Harvard Business Review, 90(10), 60-66.

[22] Lemke, T. 2001. 'The birth of bio-politics': Michel Foucault's lecture at the Collège de France on neo-liberal governmentality. Economy and Society, 30(2): 190-207.

[23] Czarniawska, B., G. Sevon. 1996. Translating Organizational Change. Berlin: Walter de Gruyter and Co.

[24] Pallas, J., M. Fredriksson, L. Wedlin. 2016. Translating Institutional Logics: When the Media Logic Meets Professions. Organization Studies, 37(11): 1661-1684.

[25] Cozzolino, A., G. Verona, F.T. Rothaermel. 2018. Unpacking the disruption process: New technology, business models, and incumbent adaptation. Journal of Management Studies, 55(7): 1166-1202.

[26] Eisenhardt, K.M., M.E. Graebner. 2007. Theory building from cases: Opportunities and Challenges. Academy of Management Journal, 50: 25-32.

[27] Strauss, A. L., J. M. Corbin. 1998. Basics of Qualitative Research: Techniques and Procedures for Developing Grounded Theory, 2nd ed. Sage, Thousand Oaks, CA.

[28] Langley, A. 1999. Strategies for theorizing from process data. Academy of Management Review, 24: 691710 .

[29] Hayward, M. 2009. Any colour you like as long as it's any colour you like. dunnhumby, London.

[30] Humby, C., T. Hunt, T.T. Phillips. 2008. Scoring Points: How Tesco Continues to Win Customer Loyalty. Kogan Page Publishers.

[31] Paavola, L. 2021. Exploring microfoundations of fieldlevel change-Essays on transformations in the retailing industries.

[32] Emirbayer, M. 1997. Manifesto for a relational sociology. American Journal of Sociology, 103: 281-317.

[33] Maguire, S., C. Hardy, T.B. Lawrence. 2004 'Institutional entrepreneurship in emerging fields: HIV/AIDS treatment advocacy in Canada. Academy of Management Journal, 47: 657-79. 